\title{
Numerical analysis of the manufacturing processes of a mock-up of the ITER NHF First Wall Panel
}

\author{
J.M. Gonzalez ${ }^{\mathrm{a}}$, M. Chiumenti $^{\mathrm{a}}$, M. Cervera ${ }^{\mathrm{a}}$, C. Agelet de Saracibar ${ }^{\mathrm{a}}$, F. Samaniego ${ }^{\mathrm{b}}$, I. Cobo $^{\mathrm{b}}$ \\ ${ }^{a}$ International Center for Numerical Methods in Engineering (CIMNE) \\ Technical University of Catalonia (UPC), Barcelona, Spain \\ josem.gonzalez@cimne.upc.edu \\ michele@cimne.upc.edu \\ miguel.cervera@upc.edu \\ agelet@cimne.upc.edu \\ ${ }^{\mathrm{b}}$ Fundación Leading Innova (CT-Innova) \\ Barrio La Agüera 39409, San Felices de Buelna, Spain \\ fsamaniego@leading.es \\ icobo@leading.es
}

\begin{abstract}
The objective of ITER is to build a new Tokamak, with the goal of demonstrating the scientific and technical feasibility of fusion power. The First Wall Panels are the inner component of the reactor, built with different materials that must support high heat flux levels inside the vacuum vessel. The manufacturing processes of the First Wall are a complex procedure including bending, hipping and cutting procedures which, in general, lead to residual stresses and distortions of the fabricated component. In this work, the analysis of the thermo-mechanical response of a simplified prototype of the ITER NHF First Wall Panel is presented from the numerical point of view. The experimental procedure within each phase of the whole manufacturing process is described. Residual stresses and distortions have been measured and analyzed. The numerical simulation of the manufacturing process includes the description of the main hypothesis, the applied loads and the boundary conditions assumed at every stage of the process. Special attention is paid to the simulation of machining and cutting by means of an $\mathrm{ad}$ hoc element deactivation strategy. The numerical results are compared with the experimental evidence to show the prediction capability and the limitations of the proposed numerical model.
\end{abstract}

\section{Introduction}

ITER is an international project involving many research centers, universities and industrial companies from different countries worldwide to develop a new and clean energy source.

The ITER reactor is based on the Tokamak concept of magnetic confinement in which the plasma is contained in a doughnut-shaped vacuum vessel (Figure 1a). The fuel, a mixture of deuterium and tritium (two hydrogen isotopes) is heated to temperatures over 150 million ${ }^{\circ} \mathrm{C}$ forming the plasma. Strong magnetic fields are used to avoid the contact between the plasma and the vessel walls. The Blanket System of ITER is the inner component of the reactor directly exposed to the plasma. The main function of the Blanket System is to provide the main thermal and nuclear shielding to the vacuum vessel or any other reactor component. Depending on their location, the First Wall (FW) panels will be able to sustain two different levels of heating loads referred to as the Normal Heat Flux (NHF - design load up to $1 \mathrm{MW} / \mathrm{m}^{2}$ ) and the Enhanced Heat Flux (EHF - design load up to $4.7 \mathrm{MW} / \mathrm{m}^{2}$ ). 
In order to reduce the eddy currents induced by the electromagnetic loading during ITER operations, the final design of the First Wall panel is cut into a number of longitudinal fingers as shown in Figure 1b. Each one of these fingers is cooled by pressurized water introduced into the cooling system at $70^{\circ} \mathrm{C}$ and extracted at $110^{\circ} \mathrm{C}$, approximately.

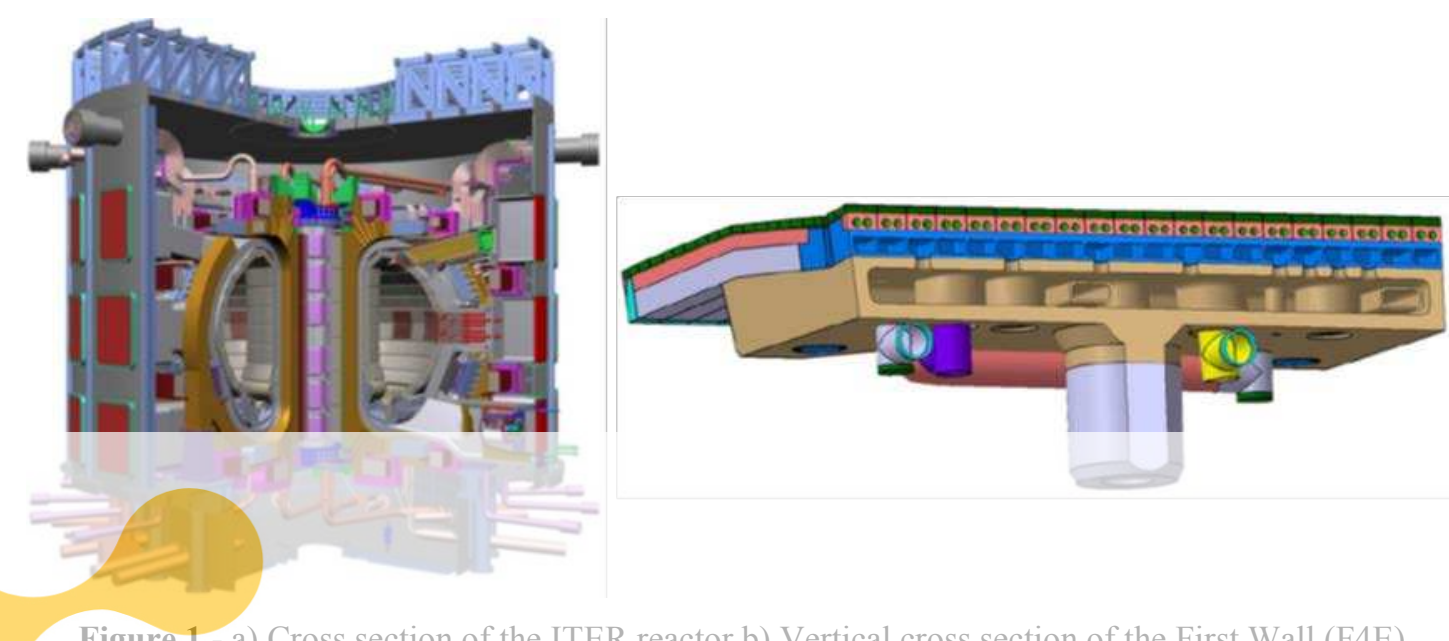

Figure 1.- a) Cross section of the ITER reactor b) Vertical cross section of the First Wall (F4E)

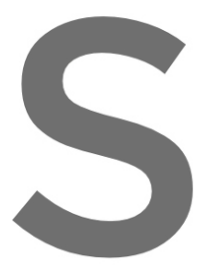

The First Wall panel is fabricated according to the following manufacturing sequence:
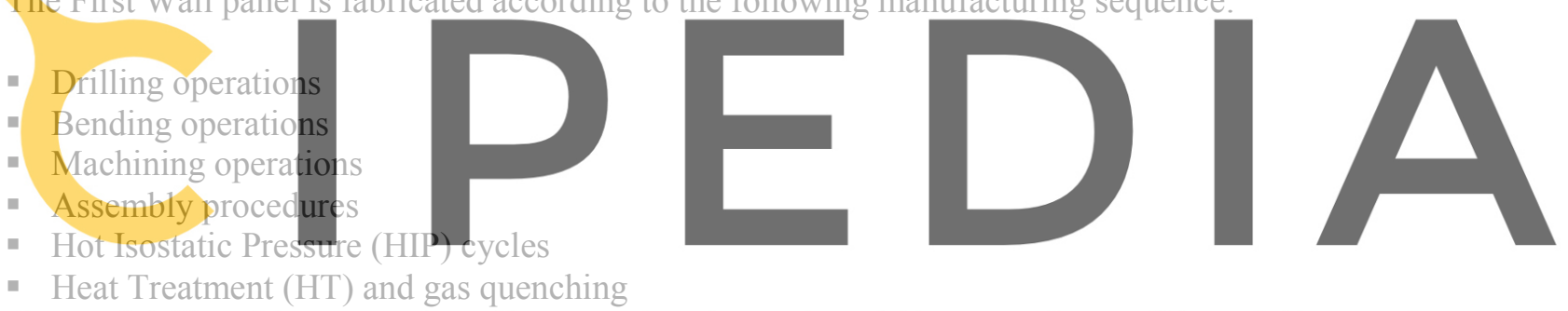

Register for freeitath hatpsthpusww.scipedia.com to download the version without the watermark

- Final Machining operations

The Hot Isostatic Pressure (HIP) cycles are used to join the Copper Chromium Zirconium $(\mathrm{CuCrZr})$ alloy to the Stainless steel (SS) structure and later to the Beryllium (Be) layer of the final arrangement [7][15][19]. These are the most critical phases of the manufacturing route because of their influence on the final distortion and residual stresses accumulated by the component. Several works have been carried out on this issue, specially about the influence over the $\mathrm{CuCrZr}$ properties [13][16][4].

The experimental work presented in this paper has been carried out by Fundación LEADING INNOVA. They provided the geometry of the mock-up, as well as the characterization of the manufacturing processes and the corresponding results to support this study.

The features of the ITER reactor and the First Wall, as well as the material properties employed to build the prototype have been provided by Fusion for Energy (F4E), the European agency for the procurement of the FW.

\section{Description of the manufacturing process}


Due to the geometrical complexity of the real components as well as the experimental and numerical strategy to study the manufacturing processes, the geometry of the First Wall Panel has been simplified [3].

At a first level of simplification, in the so called semi-prototype, the actual size has been reduced and many of the functional details have been neglected or simplified. Nevertheless, the main dimensions are kept unchanged as the length of the fingers and their section.

At a further level of simplification, the FW simple mock-up has more reduced dimensions, reduced model details and a lower number of manufacturing phases: the bending operation and the final HIP cycle used to add the Beryllium layer have not been considered.

Figure 2 shows a view of the simple mock-up and the location of the different materials used. The initial configuration is a parallelepiped-like volume, $434,4 \mathrm{~mm}$ wide and $718 \mathrm{~mm}$ long. The thickness varies between $61 \mathrm{~mm}$ and $77 \mathrm{~mm}$. The diameter of the holes is $26 \mathrm{~mm}$.
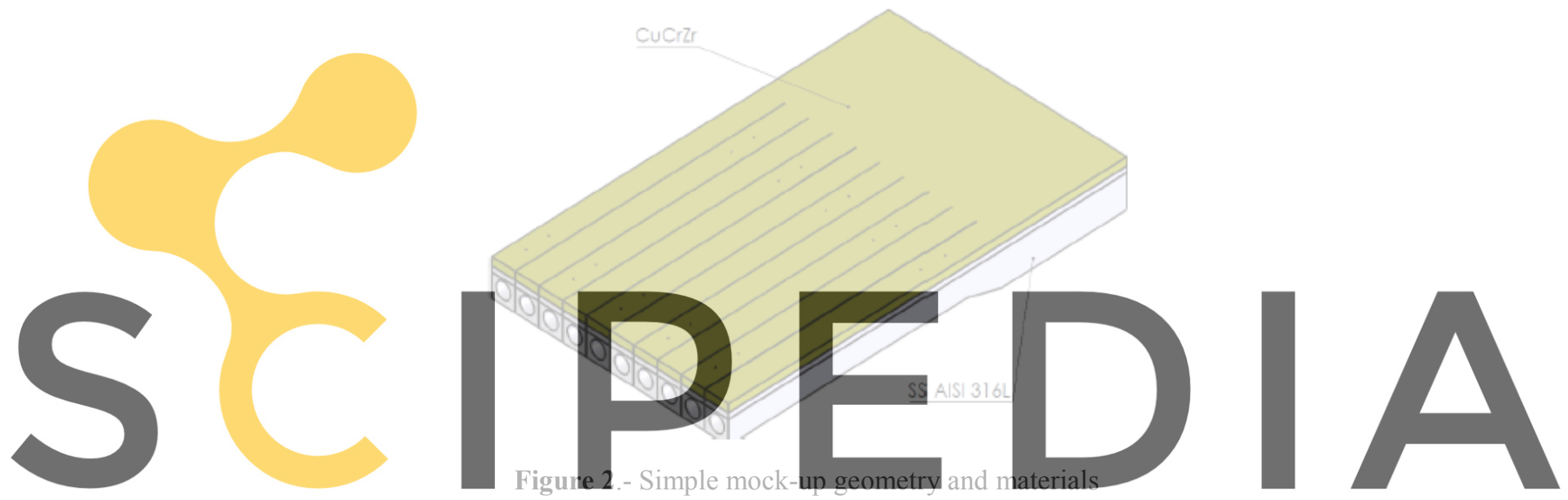
Register for free at https//www.scipedia.com to download the version without the watermark

- Machining of individual pieces

- Assembling and sealing operations

- HIP cycle for SS/CuCrZr joining

- Heat treatment (HT)

- Machining operation: top, lateral and back parts

- Fingers cutting: ten fingers $41 \mathrm{~mm}$ wide each.

- Final machining: front and back side

The objective of this paper is to study the influence of the different manufacturing stages required for the fabrication of the FW simple mock-up, and compare the numerical results obtained with the experimental evidence. To achieve such objective the component has been fabricated and both residual stresses and distortions have been measured at the end of the HIP and HT phases (once extracted from the HIP chamber) and after the machining/cutting operations at the end of the manufacturing process.

Some authors have presented a numerical approach to the HIP cycle [21][22] to support the experimental work. In this study, all the manufacturing phases have been simulated numerically by means of in-house Finite Element (FE) software adapted for this purpose. The hypothesis as well as the constitutive model adopted for the material characterization is presented in Section 4.3. Finally, Section 4.5 shows the comparison between the experimental evidence and the numerical predictions. 


\subsection{The HIP cycle}

The objective of the HIP cycle is the joint between the stainless steel and CuCrZr alloy by diffusion bonding in the interphase of both materials. This is achieved by applying simultaneously the isotropic pressure and a high temperature field according to a prescribed loading function. In a first phase, both temperature and pressure are increased simultaneously until their maximum values are reached; these values are $1040{ }^{\circ} \mathrm{C}$ and $140 \mathrm{MPa}$ for the temperature field and the isostatic pressure, respectively. The temperature and the pressure are kept constant during the second interval of $120 \mathrm{~min}$.

Finally, the applied pressure and temperature decrease to reach the initial conditions. The total duration of the HIP cycle is about 320 minutes. At the end of the HIP cycle, the joining between the SS casing and the $\mathrm{CuCrZr}$ alloy by diffusion bonding is achieved.

\subsection{The heat treatment process}

After the HIP cycle, the mock-up goes through the Heat Treatment (HT) process. The objective of this treatment is to induce the solution annealing condition to improve both mechanical and thermal properties of the CuCrZr [5].
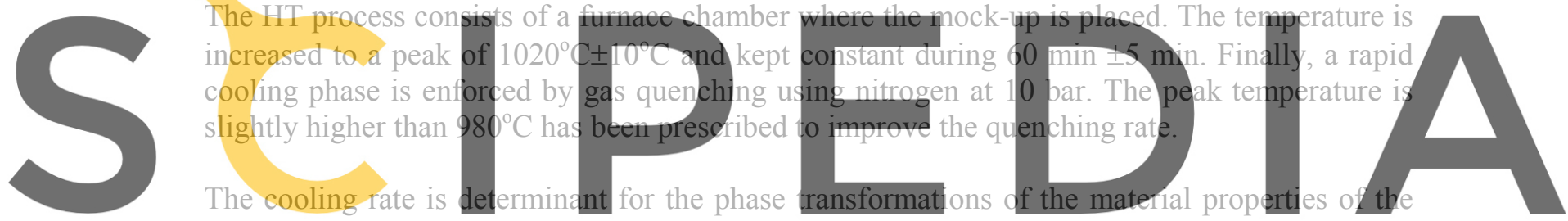

CuCrZr alloy as reported by to several studies [14][18]. This heat treatment has been carried out

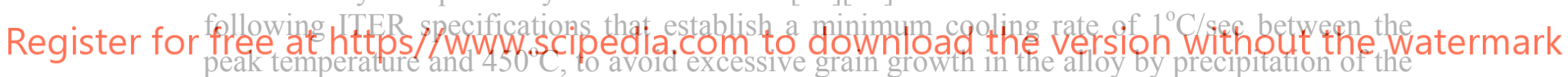
$\mathrm{Cr}$, leading to a higher strength of the $\mathrm{CuCrZr}$ alloy.

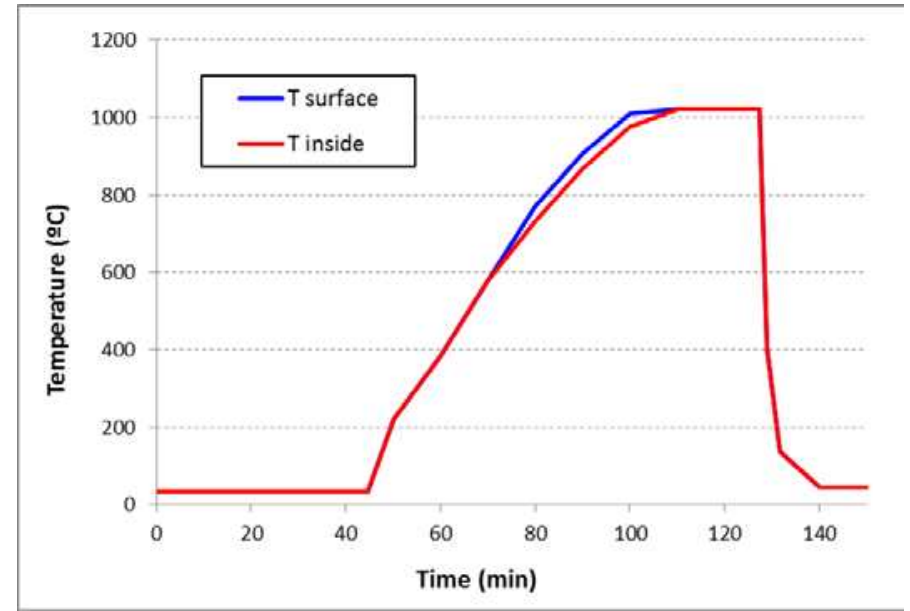

Figure 3.- Temperature evolution in the heat treatment cycle (Leading Innova)

Several measures for the temperature have been obtained in the furnace, in the surface and inside the mock-up. Three holes have been drilled in the mock-up $6 \mathrm{~mm}$ far from the bottom of 
the $\mathrm{CuCrZr}$ alloy. Thermocouples have been installed to measure the evolution of the temperature and specially the gradient between inside and outside. Both temperature curves in the mock-up during the heat treatment are shown in Figure 3.

As observed, in the heating branch in the inner points the rate of temperature is lower than outside. In the quenching, the cooling rate in the reference range of temperatures is about $3^{\circ} \mathrm{C} / \mathrm{sec}$ or higher. On the other hand, in this same quenching branch no significant differences are observed in the experimental text between inner and outer measures.

\subsection{Machining and cutting processes}

After the heat treatment, the mock-up goes through the machining process to remove the exceeding material as the top canister covering the $\mathrm{CuCrZr}$ alloy and both the lateral and back sides of the mock-up. The cutting operation to create the fingers is performed by means of Wire Electron Discharge Machining (WEDM). Observe that both cutting and machining operations are performed in isothermal conditions. In fact, the component is submerged in a water cooling pool at constant temperature. The dimensions of the mock-up after machining and cutting operations are depicted in Figure 4:
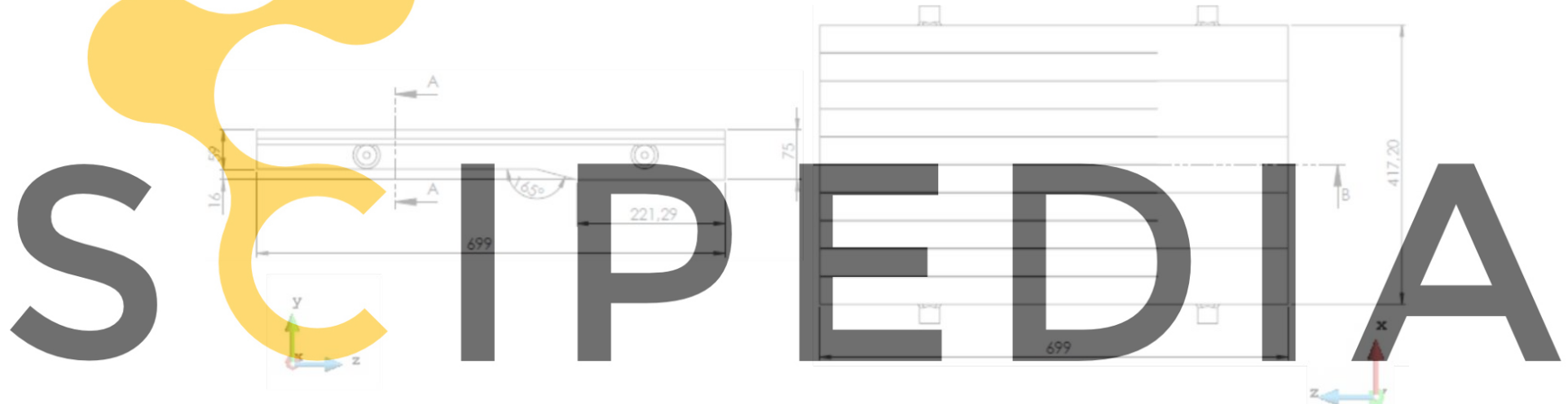

Register for free at htths/ANwwisccipedia, com to download the version without the watermark

\section{Materials}

The materials used to fabricate the simple mock-up are stainless steel (SS) 316L and CuCrZr alloy $(\mathrm{CuCrZr}-\mathrm{IG})$. The material properties of both materials are assumed as temperature dependent as shown in Figure 5.

At high temperatures, it is also important to take into account the rate-dependency of both elastic and plastic behaviors. Hence, visco-elastic and-visco-plastic constitutive laws are defined for both materials as described in Section 4.

Finally, to account for the phase transformation occurring during the HT process, the material properties are modified through a saturation law defined as:

$$
p(t)=p_{0}+\left(p_{f}-p_{0}\right)\left[1-e^{-\delta\left(t-t_{0}\right)}\right]
$$

where $p(t)$ is the generic material property (e.g. material stiffness or strength) as a function of the transformation time $t$ of the process (e.g. the HT or HIP). $p_{0}$ and $p_{f}$ are the initial and the final values of the material property at time $t_{0}$ and $t_{f}$, respectively, while $\delta$ defines the transformation rate. 


\section{Numerical simulation of the manufacturing process}

\subsection{Geometry and mesh discretization}

The geometrical model of the simple mock-up is presented in Figure 7. The actual model has been simplified by omitting all the geometrical details that do not contribute to the structural behavior of the mock-up such as the supporting devices on the lateral walls. Symmetry conditions have been considered to perform the numerical analyses on half of the geometrical model.
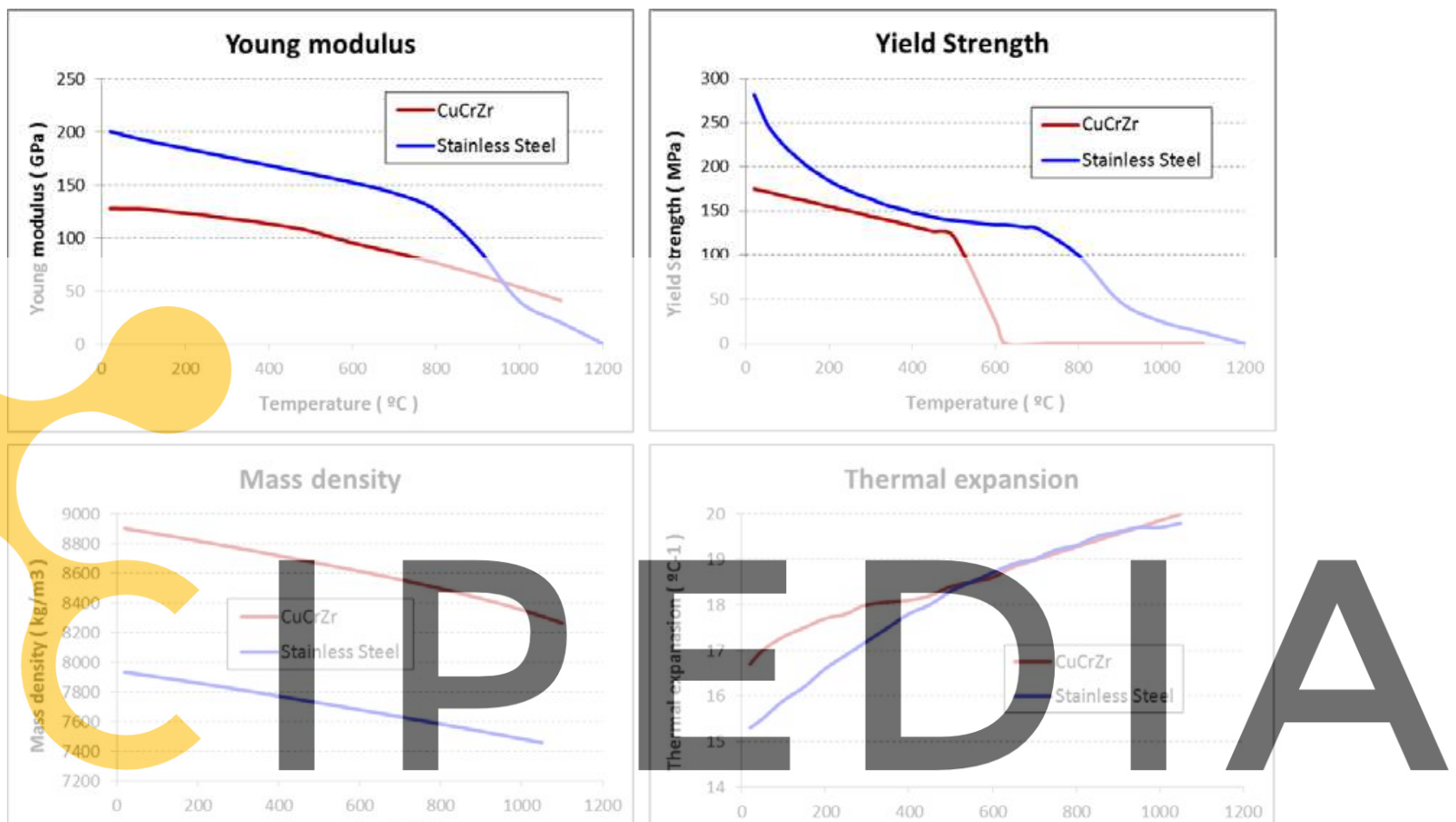

Register for free at https//wwWw.scipedia.com to download the versiorn ${ }^{2}$ without the watermark
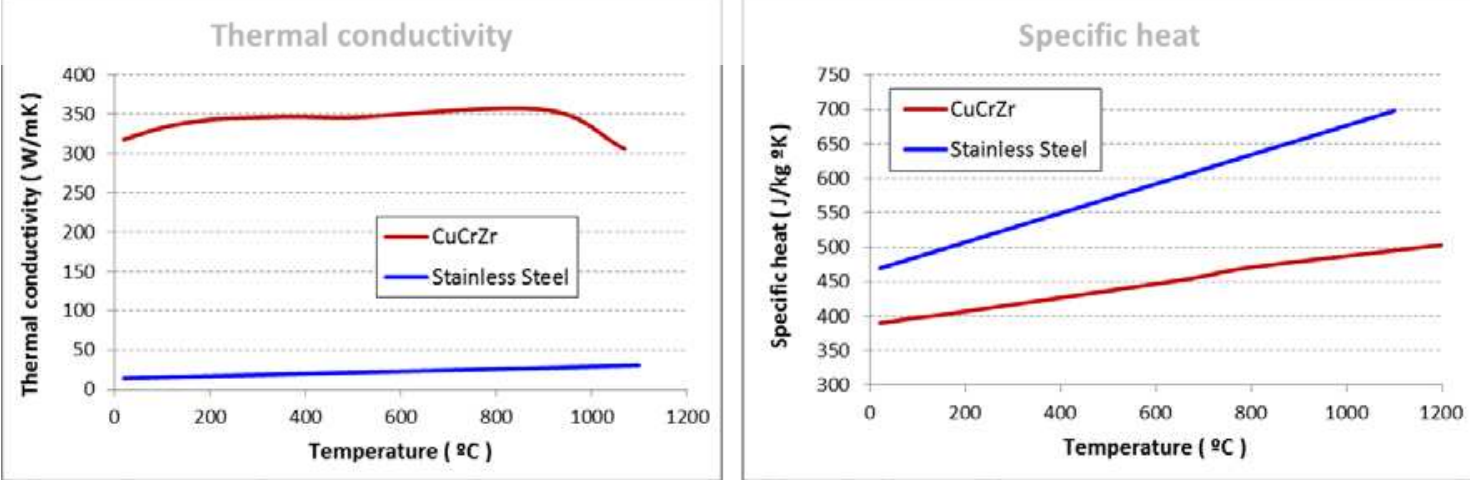

Figure 5.- Material properties for $\mathrm{CuCrZr}$ alloy and the stainless steel (F4E)

a) Young's modulus b) Yield strength

c) Density d) Thermal expansion

e) Conductivity f) Specific heat 


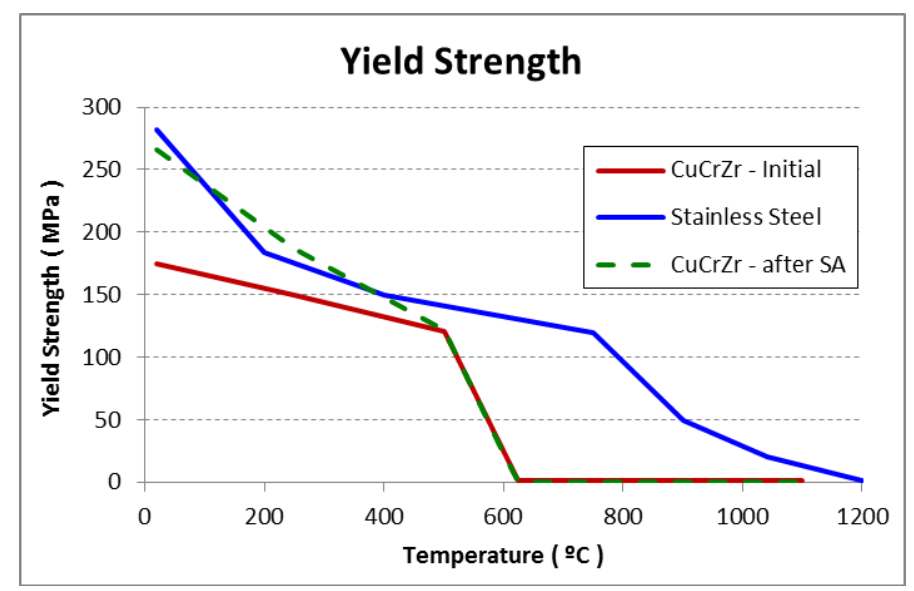

Figure 6.- Material properties for $\mathrm{CuCrZr}$ alloy and stainless steel. Variation of the yield surface due to heat treatment

The original model has been divided into different volumes to allow for the material removal during the cutting and the machining operations (see Figure 8).

The steel body is shown with blue color while the $\mathrm{CuCrZr}$ bars are depicted with the red color. The canister lid (top cover) is made of stainless steel (light brown color). It is removed after the HT. The lateral sides, made of stainless steel (green) and CuCrZr alloy (red color), are prepared to be removed by the machining operation.

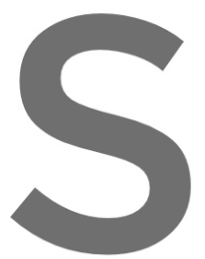

Five vertical slim la process. These layers a Finally, the front and ready to be removed by
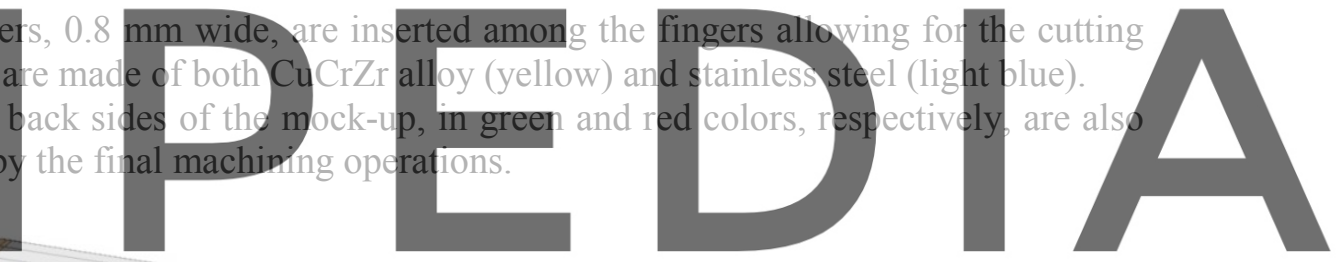

Register for free at https//www.scipedia.com to download the version without the watermark la:

Figure 7.- Model of the mock-up used for the numerical analysis 


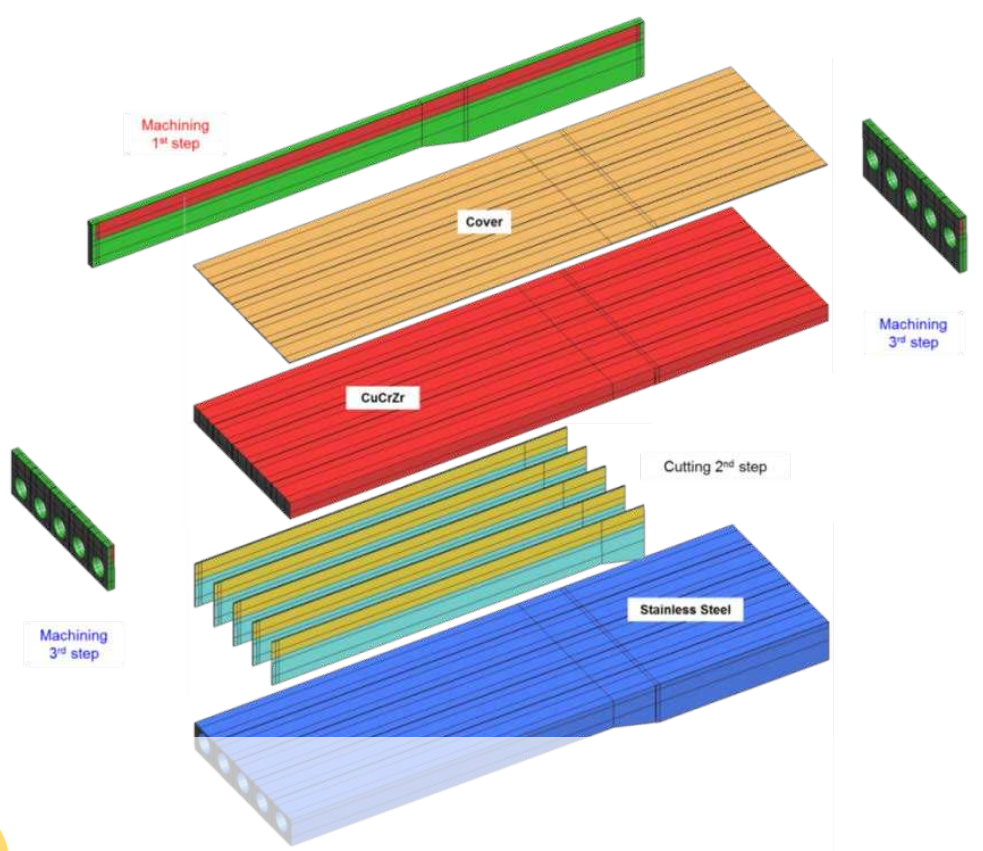

Figure 8.- Subdomains defined for the numerical simulation of the different process operations

The volume partition defined at geometrical level is preserved during the meshing strategy. To achieve optimal numerical accuracy, a structured mesh made of 23,320 hexahedral elements has

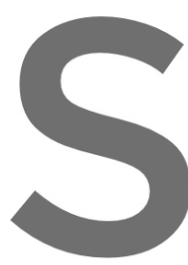
been generated with used to discretize the process of the simple
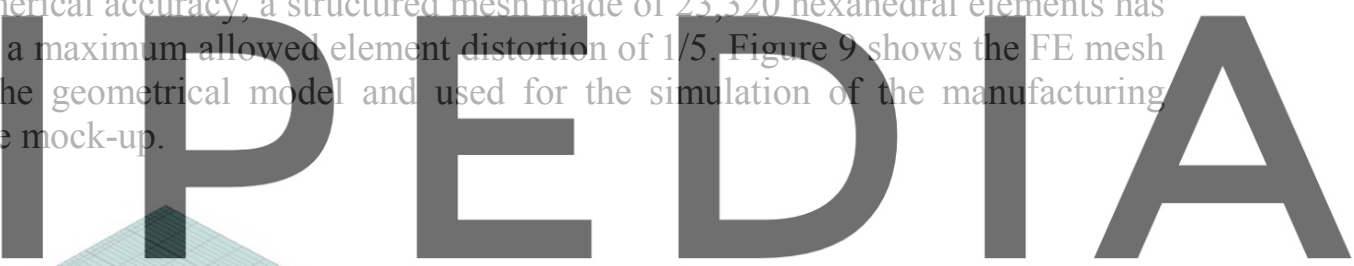

Register for free at https//www.scipedia.com to download the version without the watermark

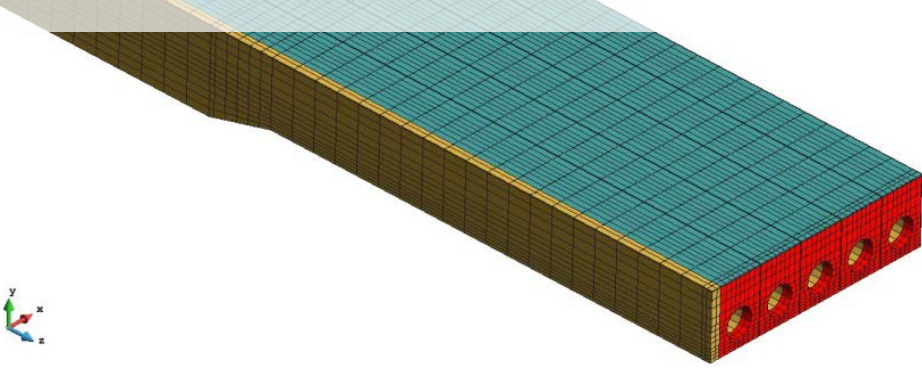

Figure 9.- Finite element mesh of the mock-up

An ad-hoc FE technology to deal with the isochoric material behavior is mandatory when the plastic deformations are purely deviatoric. This is the case for J2 visco-plastic constitutive models to describe the material behavior of metallic materials. In our work, the mixed Q1P0 FE technology is adopted to overcome the locking phenomena observed in the pressure field when standard displacement-based elements are used (see [10][20]).

\subsection{Constitutive model}


A thermo-mechanical framework is adopted for the numerical simulation of the different manufacturing phases to be considered. The governing equations as well as the constitutive equations of the model assumed in the numerical simulation are summarized in Table 1. Further details can be found in [1].

A fractional step method is used to solve in a staggered form the balance of momentum and the balance of energy equations.

Fourier's law is adopted to deal with the heat conduction being $k(\mathrm{~T})$ the temperature-dependent heat conductivity.

The heat absorption as well as the heat losses, are due to the heat convection and radiation mechanisms. The effects induced by the heat convection can be taken into account using Newton's law as:

$$
q_{\text {conv }}=h_{\text {conv }}\left(T-T_{\text {env }}\right)
$$

where $h_{\text {conv }}$ is the Heat Transfer Coefficient (HTC) by convection between the component and the surrounding environment while $T_{\text {env }}$ is the temperature. The heat loss by radiation is described by the radiation law:

$$
q_{\text {rad }}=\sigma_{\text {rad }} \varepsilon_{\text {rad }}\left(\mathrm{T}^{4}-\mathrm{T}_{\text {env }}^{4}\right)
$$

where $\varepsilon_{\text {rad }}$ is the emissivity parameter while $\sigma_{\text {rad }}$ is the Stefan-Boltzmann constant.

Both models are needed to account for the temperature field evolution applied to both HIP and

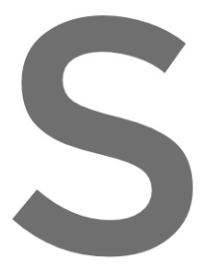

HT chambers.

A visco-elasto-visco-p
softening has been use
shows a schematic tep
visco-plastie response
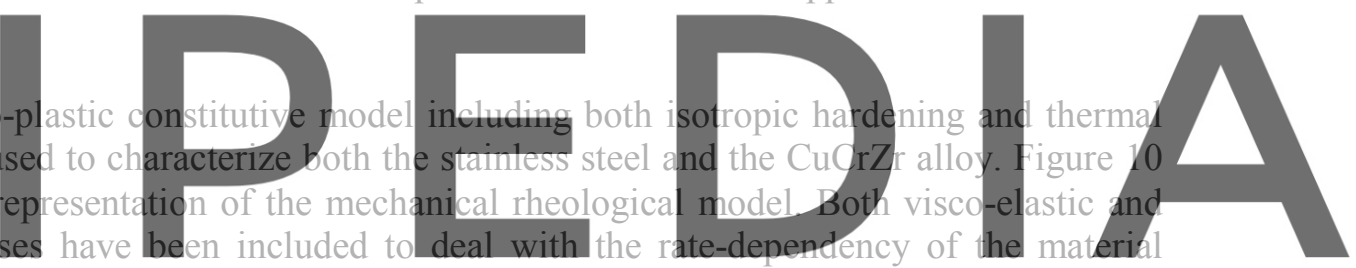

behavior at the high temperature (see [2][8][9]).

Register for free at https//www.scipedia.com to download the version without the watermark

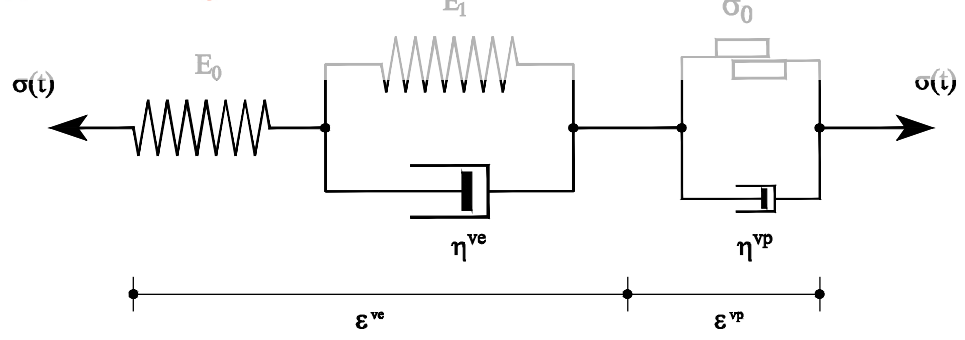

Figure 10.- Rheological scheme for the visco-elastic-viscoplatic model

The visco-elastic model depends on the elastic viscosity $\eta^{\text {ve }}$ so that the material stiffness can vary from its initial value $E_{0}(\mathrm{t}=0)$ to the final stiffness $\mathrm{E}_{\infty}(\mathrm{t} \rightarrow \infty)$ defined as:

$$
E_{\infty}=\frac{E_{0}+E_{1}}{E_{0} E_{1}}
$$

The elastic limit $\sigma_{0}$ is a critical temperature-dependent material parameter that is progressively reducing while the temperature is increased. When the temperature is close to the melting temperature the yield surface radius vanishes and the mechanical response for both mushy and liquid-like phases is purely viscous being $\eta^{\mathrm{vp}}$ the associated plastic viscosity. 
The isotropic hardening is defined by the saturation stress $\sigma_{\infty}$ and the linear hardening coefficient $H$. Note that he melting temperature is assumed as annealing temperature. Hence, the strain hardening is reset above such temperature.

Finally, the thermal shrinkage depends on the thermal expansion coefficient $\alpha(T)$ and the initial temperature $\mathrm{T}_{0}$ defined for each material.

\section{Thermal model}

- Balance of energy equation

$$
\dot{H}=-\nabla \cdot \boldsymbol{q}
$$

- Enthalpy rate

$$
\dot{H}(\mathrm{~T})=C(\mathrm{~T}) \dot{T}
$$

- Fourier's law for heat conduction

$$
\boldsymbol{q}=-k(\mathrm{~T}) \nabla \mathrm{T}
$$

- Convection heat flux

$q_{\text {conv }}=h_{\text {conv }}\left(\mathrm{T}-\mathrm{T}_{\text {env }}\right)$

- Radiation heat flux

$$
q_{\text {rad }}=\sigma_{\text {rad }} \varepsilon_{\text {rad }}\left(\mathrm{T}^{4}-\mathrm{T}_{\text {env }}^{4}\right)
$$

\section{Mechanicall model}

- Total strain

- Thermal deformation

- Stress tensor decomposition

$$
\begin{gathered}
\boldsymbol{\varepsilon}=\nabla^{S} \boldsymbol{u} \\
\varepsilon^{\Theta}=3\left[\alpha(T)\left(\mathrm{T}-\mathrm{T}_{\text {ref }}\right)-\alpha\left(\mathrm{T}_{0}\right)\left(\mathrm{T}_{0}-\mathrm{T}_{\text {ref }}\right)\right]
\end{gathered}
$$

Balance of momentum equation (split format)

$$
\sigma=p I+s(\boldsymbol{u})
$$
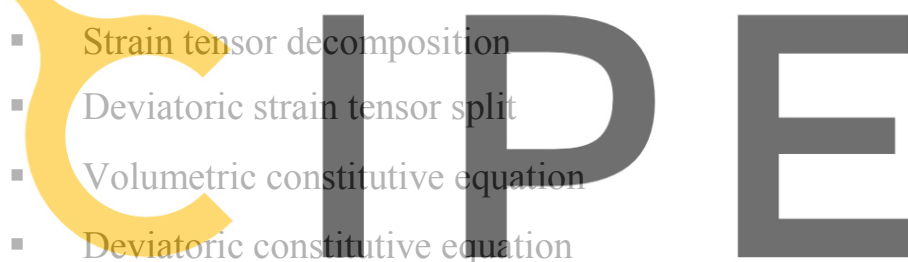

$\nabla \cdot s(\boldsymbol{u})+\nabla p+\mathrm{f}=0$

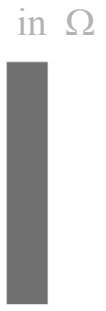

Yield surface

Register for free at https//www.scipedia.com to download the version without the watermark

- Von Mises yield surface radius

- Isotropic hardening

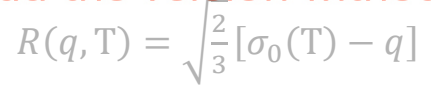

$$
q=-\left[\sigma_{\infty}-\sigma_{0}\right]\left(1-e^{-\delta \xi}\right)-H \xi
$$

- Evolution law for the plastic deformation

$$
\begin{aligned}
& \dot{\boldsymbol{\varepsilon}}^{v p}=\gamma^{v p} \frac{\boldsymbol{s}}{\|\boldsymbol{s}\|} \\
& \dot{\xi}=\sqrt{\frac{2}{3}}\left\langle\frac{\Phi(s, q, \mathrm{~T})}{\eta_{p}}\right\rangle=\sqrt{\frac{2}{3}} \gamma^{v p}
\end{aligned}
$$

Table 1.- Governing equations, constitutive laws and evolution law describing the thermo-visco-elastovisco-plastic constitutive model

Table 2 shows a list with the material properties to define the constitutive model, their notation and temperature dependence.

\begin{tabular}{|l|c|}
\hline Property name & Notation \\
\hline Specific heat & $\mathrm{C}(\mathrm{T})$ \\
\hline Conductivity & $\mathrm{k}(\mathrm{T})$ \\
\hline Emissivity & $\varepsilon_{\text {rad }}$ \\
\hline Convection coefficient & $\mathrm{h}_{\text {conv }}$ \\
\hline Young's modulus & $\mathrm{E}(\mathrm{T})$ \\
\hline
\end{tabular}




\begin{tabular}{|l|c|}
\hline Poisson's ratio & $v(T)$ \\
\hline Thermal expansion coefficient & $\alpha(T)$ \\
\hline Elastic viscosity & $\eta_{\mathrm{ve}}(\mathrm{T})$ \\
\hline Plastic viscosity & $\eta_{\mathrm{vp}}(\mathrm{T})$ \\
\hline Initial flow stress limit & $\sigma_{0}(\mathrm{~T})$ \\
\hline Saturation stress limit & $\sigma_{\infty}(\mathrm{T})$ \\
\hline Linear hardening parameter & $\mathrm{H}$ \\
\hline
\end{tabular}

Table 2.- Material properties in the thermo-visco-elasto-visco-plastic constitutive model

\subsection{Simulation of the HIP and HT processes}

A fully coupled thermo-mechanical analysis is considered to analyze both the HIP and HT cycles. Figure 11 shows the pressure and temperature functions used in the experiment. The same thermo-mechanical loading is applied in the numerical model.

The following assumptions have been made for the numerical modeling of the HIP phase:

1) Stress-free thermal expansion of the stainless steel casing is ensured by the isostatic boundary condition of the supporting structure used to fix the mock-up in the HIP chamber.

2) Free dilatation of the stainless steel with respect to the $\mathrm{CuCrZr}$ bar during the heating phase.

3) Perfect bonding between stainless steel and $\mathrm{CuCrZr}$ alloy is assumed at the end of the HIP plateau when the highest temperature and pressure field is applied in the HIP chamber. This is imposed by linking the surface nodes at the contact interface between the steel and the $\mathrm{CuCrZr}$ alloy.

4) When the maximum temperature is reached for both HIP and HT phases, the $\mathrm{CuCrZr}$ alloy is in a mushy phase [6]. Its yield strength is negligible and the annealing effect resets the phase transformation hardening due to previous plastic deformations as shown in Figure $5 b$.

5) The residual stresses are generated during the cooling phase of both HIP and HT cycles due to the different thermal expansion coefficients of the two materials once the joining is completed by diffusion bonding. Note that these stresses take place below $600^{\circ} \mathrm{C}$ when the strength of the $\mathrm{CuCrZr}$ alloy is reestablished.

6) In case of high cooling rates (that's HT process) the material properties of the $\mathrm{CuCrZr}$ alloy are modified to take into account the phase transformation. Hence, a different set of material properties is used during cooling if compared to the one used during the heating phase (see Eq. 1).

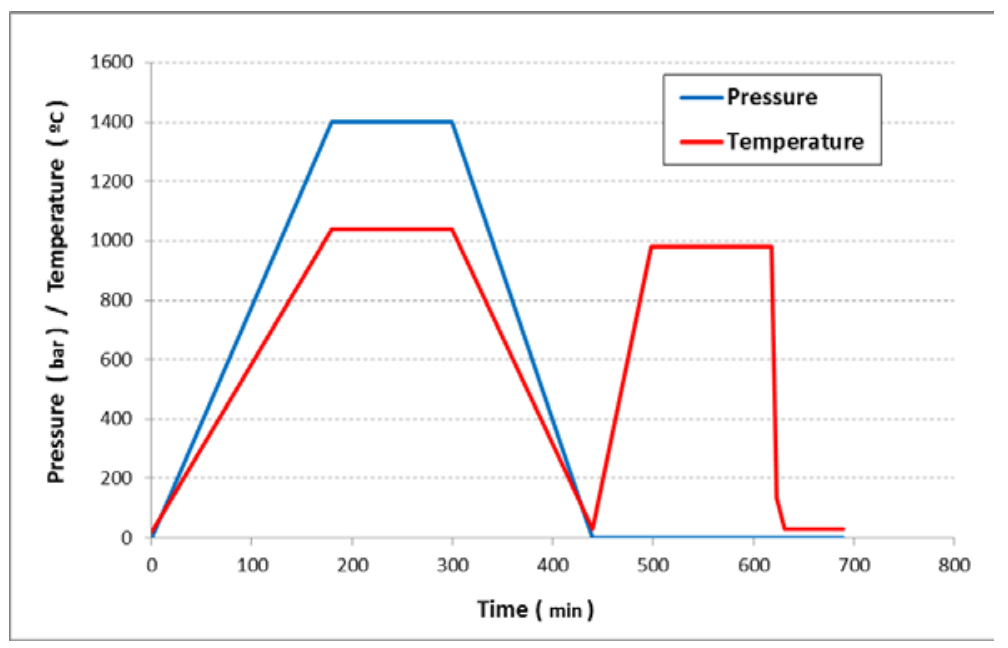


Figure 11.- Evolution of the pressure [bars] and temperature $\left[{ }^{\circ} \mathrm{C}\right]$ applied to the mock-up during the HIP process and the HT treatment. (F4E)

\subsection{Simulation of the machining and cutting phases}

The final dimensions of the mock-up are obtained after machining and cutting operations. Both of them take place in isothermal conditions: the component is submerged in a water cooling pool at constant temperature. Hence, a purely mechanical analysis is performed according to the following hypotheses:

1) The residual stresses and distortions induced by HIP and HT cycles are the starting point for machining and cutting process.

2) The same mesh is assumed for the next phases without requiring any data transfer or smoothing techniques.

3) The machining and cutting processes are performed by deactivating the elements in the sets that correspond to the volumes removed during such operations [11]. The cutting planes have been previously inserted as part of the CAD geometry and preserved during the meshing operation as described in Section 4.1.

4) Cutting and machining operations are very local processes. The global response (distortion) of the component is only affected by the stress redistribution and stress relaxation while removing the material.

5) At room temperature and very slow cutting speed the material behavior can be assumed as temperature and rate independent. Consequently, the cutting speed does not affect the final results.

\subsection{Numerical results}

\subsubsection{Quality control measurements during manufacturing}

In this section the results obtained through the numerical simulation are compared with those coming from the experimental measurements. Particular attention is focused on the values of the residual stresses and the distortion of the mockup at the end of the manufacturing process.

A dimensional control is performed after HIP and HT phases once the mock-up is extracted from the HIP chamber. Once the steel canister is removed, stresses and strains have been measured using 3 strain-gauges placed on the top surface of the $\mathrm{CuCrZr}$ alloy. The measurements took place during the entire cutting/machining phase to monitor the stress released during to the cutting operation.

A further dimensional control is used to check the effects induced by the cutting process as well as to assess the final distortions induced by the entire manufacturing chain.

\subsubsection{Residual stress evolution}

Before cutting of the fingers, a set of strain-gauges has been placed over the $\mathrm{CuCrZr}$ surface. The location of the gauges is shown in Figure 12a. The evolution of the in-plane stresses $\left\{\sigma_{x}, \sigma_{z}\right\}$ have been measured during the cutting phase. Figure $12 \mathrm{~b}$ shows the location where the normal stresses have been obtained from the numerical simulation. The comparison between experimental measurements and numerical results are shown in Figure 13.

Note that the stresses reported are relative to the values before cutting (after HIP and HT). The in-plane stresses are presented using two curves: the first one on the $\mathrm{CuCrZr}$ surface just after the upper canister is machined $\left(\sigma_{\mathrm{x}, \mathrm{z}}\right.$-Sur). The second one, in the same location but obtained by 
hole-drilling through the CuCrZr bars $\left(\sigma_{\mathrm{x}, \mathrm{z}}-\mathrm{In}\right)$. Shear stresses are negligible as shown by the very low values obtained through the experimental measurements and the numerical simulation.
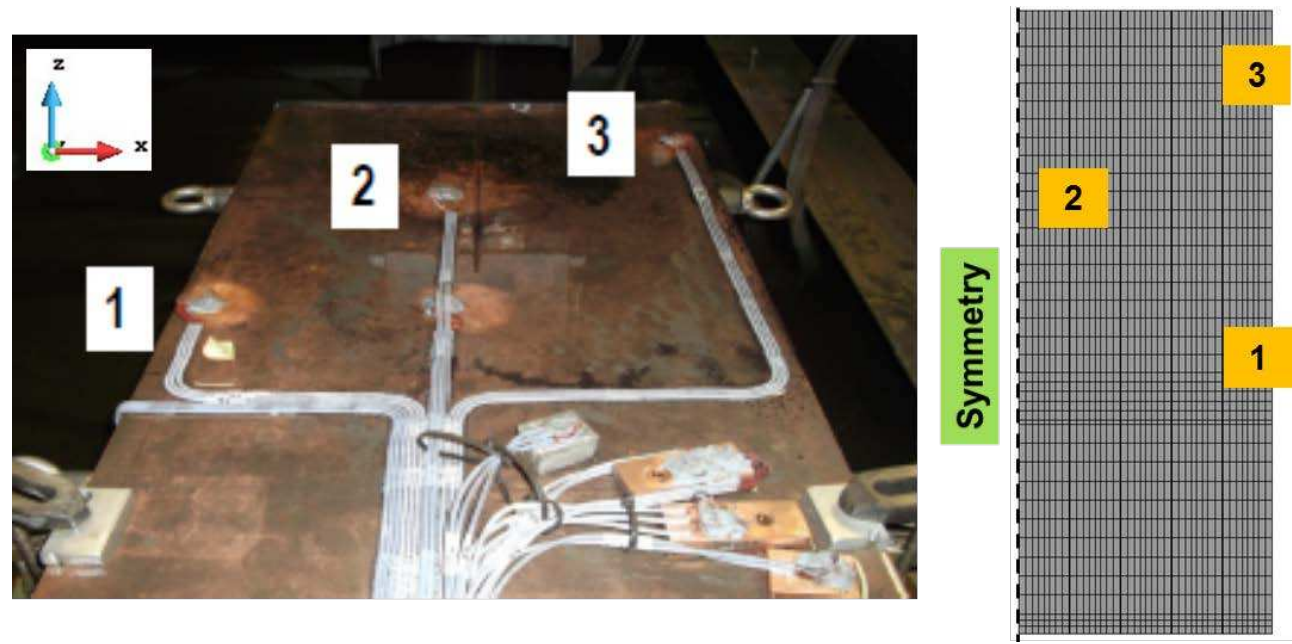

Figure 12.- Location of the strain gauges over the simple mock-up before machining/cutting phase a) Experimental setup b) Numerical postprocess points

It can be observed that even if the global trend is somehow captured, the actual values are quite different. This is probably due to the large variation of the residual stresses through the thickness of the mockup as can be appreciated comparing surface and inside curves. This stress gradient cannot be captured by the hole-drilling method which returns an average value based on the stress release once the hole is made. The solution is quite different in the numerical model, because the FE representation is able to return the corresponding stress values once defined the exact locations to be extracted. The numerical analysis clearly shows the high stress gradient varying from the external surface to the actual penetration of the drill.
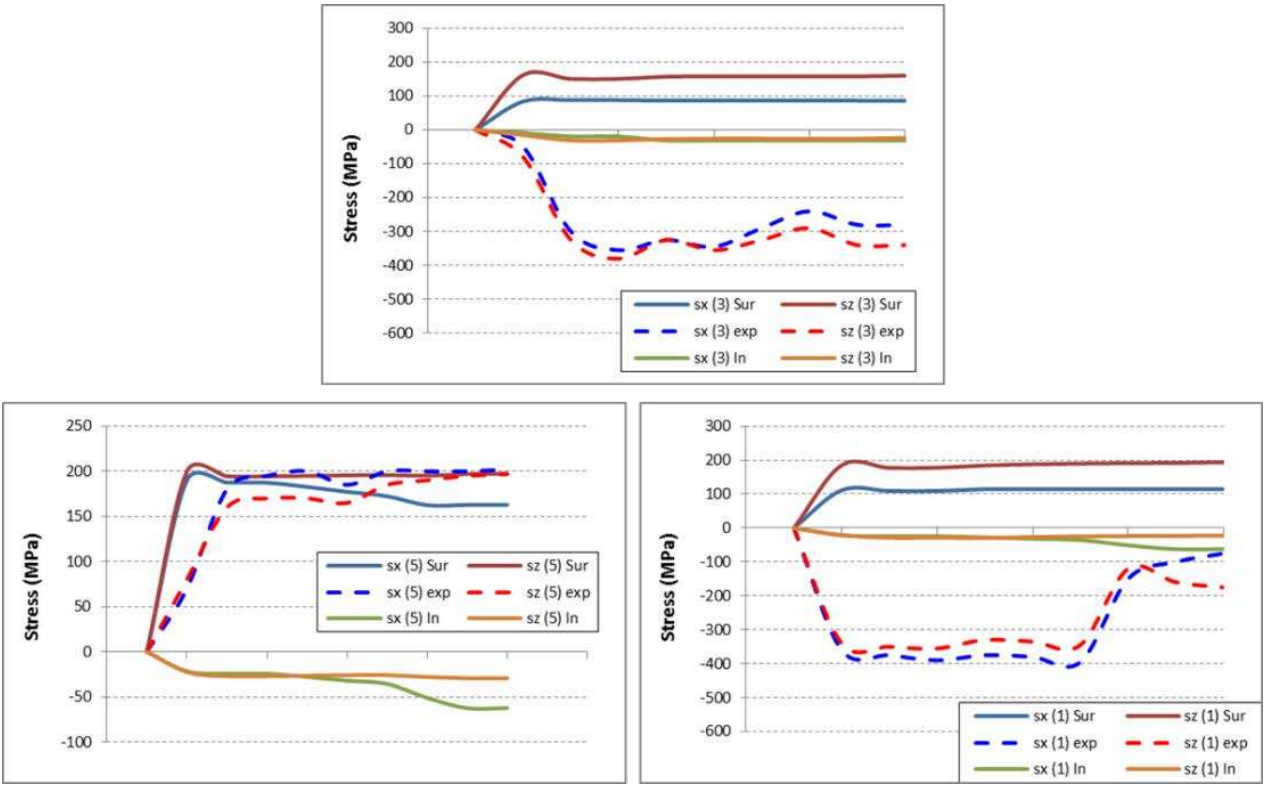

Figure 13.- Evolution of the stresses $\left\{\sigma_{x}, \sigma_{z}\right\}$ at two strain-gauge locations during the machining/cutting phase: experimental measurements (Leading Innova) vs numerical analysis.

\subsubsection{Transversal displacements}


The transversal displacements of the front side of the mock-up of the mock-up fingers obtained after the cutting/machining operations are shown in Figure 14. The experimental measurement is taken over the top surface of the mock-up, in the mid-point of each finger.

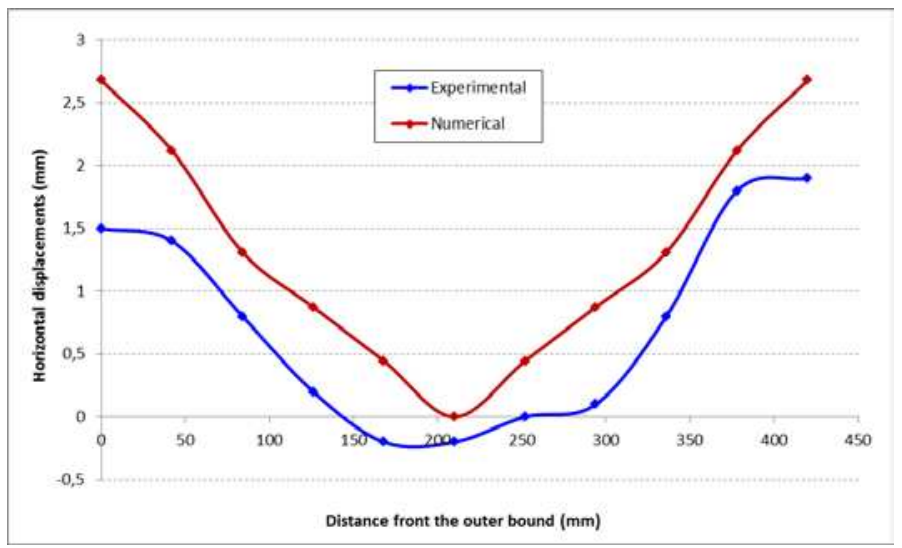

Figure 14.- Transversal distortion of the mock-up in terms of horizontal displacements of the fingers: experimental measurements (Leading Innova) vs. numerical analysis

The numerical analysis results in good agreement with the experimental measurements. It must be pointed out that the numerical results take advantage from the symmetry plane with respect to the longitudinal mid-plane of the mock-up. The experimental evidence shows a different behavior on the two sides of the component. This could be attributed to either the non-identical clamping conditions during the manufacturing operation or to the cutting sequence which generates a non-symmetric stress release.

\subsubsection{Vertical displacements}

The distortion of the mock-up along the vertical direction is very relevant for the final performance of the component. Also in this case, the cutting procedure results in a differential movement among fingers. The numerical analysis shows that the maximum vertical displacement corresponds to the more external fingers while reducing its amplitude for the more internal ones. Figure 15 compares the numerical results with the experimental evidence. Once again the comparison is not fully satisfactory.

The experimental measurements show how the more external fingers present the larger vertical movement as predicted by the numerical model. However, an inverted curvature of the inner part is an unexpected result. Due to the simplification made on the geometry proposed for the mock-up, it is difficult to expect such a structural response. Moreover, previous fabrications of semi-prototypes have induced a final distortion very similar to the result of the numerical analysis shown in this work.

A possible explication for the actual distortion obtained could be either a non-perfect diffusion bonding after the HIP process at the contact interface between Stainless Steel and CuCrZr alloy or non-homogeneous material properties induced by the HT process. Hence, after cutting, the inner part of the mock-up presents a different structural behavior compared to the more external zones. Those possibilities have not been accounted for in the numerical model. In fact, the diffusion bonding has been simulated as perfect sticking between the surfaces of the 2 materials in contact at the end of the HIP plateau, and homogeneous properties have been assumed for each material. 


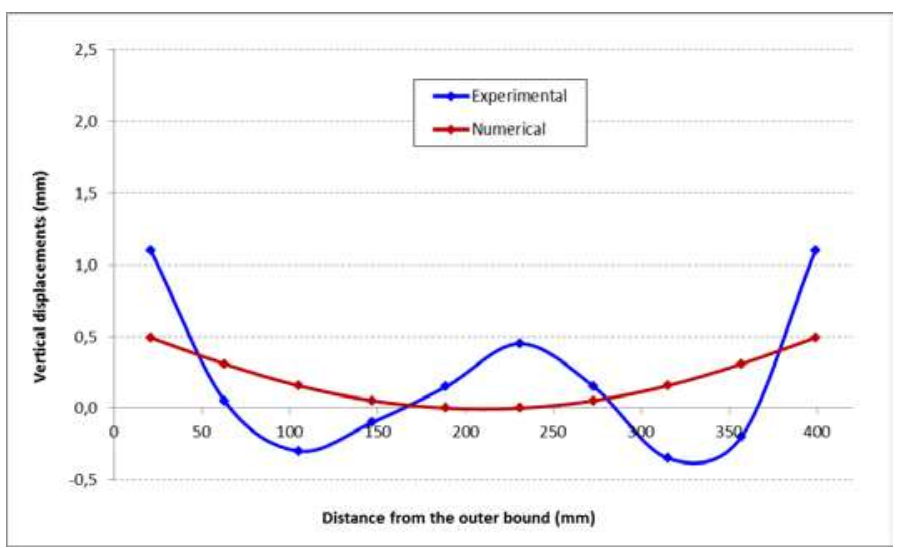

Figure 15.- Vertical distortion of the mock-up in terms of vertical displacements of the fingers: experimental measurements (Leading Innova) vs. numerical analysis

\section{Conclusions}

The simplified prototype of the ITER First Wall has been fabricated. The numerical analysis of the different phases of the entire manufacturing process has been presented making use of a fully coupled thermo-mechanical solution. HIP, heat treatment, machining and cutting operations have been simulated. A suitable fully temperature dependent visco-elastic viscoplastic constitutive model has been proposed, including strain hardening, thermal softening, annealing and phase transformation contributions.

The thermo-mechanical loading in terms of temperature and pressure evolution has been prescribed as for the actual processing. The machining and cutting sequences have been considered following the fabrication procedure.

Perfect sticking between stainless steel casing and $\mathrm{CuCrZr}$ alloy due to diffusion bonding has been assumed at the end of the HIP plateau.

The phase transformation induced by the rapid cooling during HT has been modeled by a saturation law able to modify the material properties from their initial values (before HT) to their final values (higher stiffness and strength induced by the the HT process).

Both cutting and machining operations have been modeled by an element deactivation process which removes the material according to the cutting sequence.

Experimental measurements have been carried out by LEADING INNOVA to understand the consequences induced to the mock-up by the subsequent manufacturing phases in terms of the final distortion and residual stresses. Hence, the hole-drilling method has been used to measure the stress/strain evolution during the entire cutting process. Moreover, a dimensional control after HIP and HT processes and after the cutting/machining operations has been recorded.

The comparison between the numerical results and the experimental evidence has demonstrated the prediction capabilities of the numerical procedure proposed. Nevertheless, the agreement with the experimental evidence was not always fulfilled. It must be remarked the complexity of both the fabrication processes as well as the difficulties encountered while simulating the entire fabrication chain. Moreover, on one hand, more precise techniques are necessary to improve the measurements of residual stresses such as neutron diffraction methods. On the other hand, more sophisticated constitutive models including microstructure evolution law are welcome to tackle both the diffusion bonding during HIP and the phase transformation during the HT process. 


\section{Acknowledgements}

The design and the fabrication of the 10 fingers mock-up as well as the experimental measurements by LEADING METAL-MECHANIC SOLUTIONS and Fundación LEADING INNOVA are gratefully acknowledged.

The work leading to this publication has been partially funded by Fusion for Energy under Contract F4E-OPE-589. This publication reflects the views only the authors, and Fusion for Energy cannot be held responsible for any use which may be made of the information contained therein.

\section{References}

[1] Agelet de Saracibar, C., Cervera, M. and Chiumenti, M., "On the formulation of coupled thermoplastic problems with phase-change", Int. Journal of Plasticity, 15 (1999) 1-34

[2] Agelet de Saracibar, C., Chiumenti, M., Cervera, M., Dialami, N. and Seret, A. "Computational modeling and sub-grid scale stabilization of incompressibility and convection in the numerical simulation of friction stir welding processes". Archives of Computational Methods in Engineering, 21 (2014) 3-37.

[3] Banetta S. et al., "Manufacturing of small-scale mock-ups and of a semi-prototype of the ITER Normal Heat Flux First Wall" Fusion Engineering and Design. (2014).

[4] Banetta S., Bellin B., et al. "Manufacturing and testing of a ITER First Wall semiprototype for EUDA pre-qualification" Fusion Engineering and Design 98-99 (2015) 1211-1215.

[5] Barabash V.R., Kalinin G.M. et al. "Specification of $\mathrm{CuCrZr}$ alloy properties after various thermo-mechanical treatments and design allowables including neutron irradiation effects" Journal of Nuclear Materials 417 (2011) 904-907.

[6] Biswas, S., Sket, F., Chiumenti, M., Gutiérrez-Urrutia, I., Molina-Aldareguía, J.M., and Pérez-Prado, M.T.. "Relationship between the 3D porosity and B-phase distributions and the mechanical properties of a high pressure die cast AZ91 Mg alloy". Metallurgical and Materials Transaction A, 44(9) (2013) 4391-4403.

[7] Cédat D., Bobin I., Boireau B., Bucci P., Lorenzetto P. "Optimisation of hot isostatic pressing bonded SS/SS joints conditions for ITER blanket shield" Fusion Engineering and design 87 (2012) pps: 1461-1465.

[8] Cervera, M., Agelet de Saracibar, C. and Chiumenti, M., Thermo-mechanical analysis of industrial solidification processes, Int. Journal for Num. Methods in Engineering, 46 (1999) 1575-1591.

[9] Chiumenti, M., Agelet de Saracibar, C. and Cervera, M., On the Numerical Modeling of the Thermo-Mechanical Contact for Metal Casting Analysis, Journal of Heat Transfer, 130, (2008), 1-10.

[10] Chiumenti, M., Valverde, Q., Agelet de Saracibar, C. and Cervera, M. A stabilized formulation for incompressible plasticity using linear triangles and tetrahedra, Int. Journal of Plasticity, 20 (2004) 1487-1504.

[11] Chiumenti, M., Cervera, M., Salmi, A., Agelet de Saracibar, A., Dialami, N. and Matsui, $\mathrm{K}$. "Finite element modeling of multi-pass welding and shaped metal deposition processes". Computer Methods in Applied Mechanics and Engineering, 199 (2010) 23432359.

[12] Cicero T. at el. "Progress in the design of Normal Heat Flux First Wall panels for ITER" Fusion Engineering and Design (2015).

[13] Gillia O., Briottet L., et al. "Characterization of $\mathrm{CuCrZr}$ and $\mathrm{CuCrZr} / \mathrm{SS}$ joint strength for different blanket components manufacturing conditions". Journal of Nuclear Materials 386-388 (2009) 830-833

[14] Ivanov A.D., Nikolaev A.K., at al. "Effect of heat treatments on the properties of CuCrZr alloys" Journal of Nuclear Materials 307-311 (2002) 673-676. 
[15] Le Marois G., Dellis Ch., Gentzbittel J.M., Moret F. "HIPing of copper alloys to stainless steel". Journal of Nuclear Materials 233-277 (1996) 927-931.

[16] Lorenzetto P., Banetta S., et al. "EU contribution to the procurement of the ITER blanket first wall" Fusion Enginering and Design 109-111 (2016) 661-665.

[17] Ordas N., Samaniego F., et al "Mechanical and microestructural characterization of HIP joints of a simplified prototype of the ITER NHF First Wall Panel" Fusion Engineering and Design 124 (2017) 999-1003.

[18] Park J-Y., Lee J-S. et al. "Effect of cooling rate on mechanical properties of aged ITERgrade CuCrZr" Fusion Engineering and Design 83 (2008) 1503-1507.

[19] Sato S., Kuroda T., Hatano T., Furuya K., Tokami I., Takatsu H. "Development of first wall blanket structure by hot isostatic pressing (HIP) in the JAERI". Fusion Engineering and Design 39-40 (1998) 609-614.

[20] Valverde Q., Agelet de Saracíbar C., Cervera M., Chiumenti M. "Elementos estabilizados de bajo orden en mecánica de sólidos". CIMNE monograph n ${ }^{\circ}$ 69. December 2002.

[21] Wikman B., Svoboda A., Haggblad H-A. "A combined material model for numerical simulation of hot isostatic pressing" Computer methods in applied mechanics and engineering 189 (2000) 901-913.

[22] Yuan W.X., Mei J., Samarov V., Seliverstov D., Wu X., "Computer modelling and tooling design for near net shaped components using hot isostatic pressing" Journal of Materials Processing technology 182 (2007) 39-49. 